\title{
Agronomic
}

Journal pê

\section{FRAÇõES OXIDÁVEIS DA MATÉRIA ORGÂNICA EM ÁREAS DE INCÊNDIO NA MICROREGIÃO DA CHAPADA DOS VEADEIROS}

\author{
OXIDABLE FRACTIONS OF ORGANIC MATTER IN FIELDS OF FIRE IN THE CHAPADA \\ MICROREGIÃO OF THE VEHICLES
}

Sillas Martins Mendonça ${ }^{1}$; Rodrigo Fernandes de Souza ${ }^{2}$; Jadson Belém de Moura ${ }^{2}$; Wagner Gonçalves Vieira Júnior ${ }^{3}$, Diogo Jânio de Carvalho Matos4; Julio César Silva ${ }^{2}$, Elivan César Vieira Rocha ${ }^{2}$; Sara Raquel Mendonça ${ }^{1}$, Quétsia Guedes dos Santos Silva ${ }^{5}$, Rodrigo Martins Moreira ${ }^{6}$

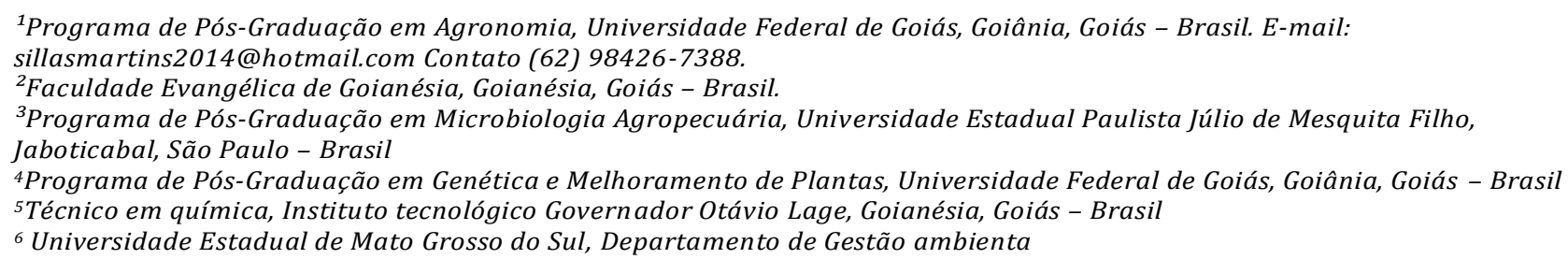

${ }^{3}$ Acadêmico do curso de Agronomia, do Instituto Federal de Ciência, Educação e Tecnologia Goiano - campus Rio Verde

\section{Resumo}

\section{Info}

Recebido: 01/2019

Publicado: 06/2019

ISSN: 2595-6906

\section{Palavras-Chave \\ Fitofisionomias, Chapada dos \\ Veadeiros, Degradação.}

\section{Keywords:}

Phytophysiognomies, Chapada of the Veadeiros, Degradation Limpo e Campo Sujo, foram encontrados os maiores valores para os solos sem queimadas, no Stricto Senso obteve maiores valores em solo de queimadas. matéria orgânica, que contem em sua composição $58 \%$ de Carbono Orgânico. Com o presente trabalho objetivou-se determinar as frações oxidáveis do carbono, em solos do parque nacional chapada dos veadeiros. As áreas foram divididas entre solos queimados e não queimados em três fitofisionomias: Campo Limpo, Campo Sujo, e Stricto Senso. Quando foram comparadas as fitofisionomias o Campo Limpo e Campo Sujo, apresentaram um maior incremento do COT ao decorrer do tempo, com índices maiores em solos de queimadas, diferenciou-se do Stricto Senso onde ocorreu de forma contrária. Nas frações F1+ F2, Campo Limpo e Campo Sujo obtiveram um aumento relevante em solos de queimadas, em Stricto Senso houve uma maior queda nos valores tendo o solo sem queimadas com maior quantidade de carbono. Nas frações F3+F4 no Campo

Um dos melhores indicadores na qualidade do solo está à

Abstract

One of the best indicators of soil quality is organic matter, which contains $58 \%$ of organic carbon. The objective of this work was to determine the oxidizable fractions of carbon, in soils of the national park Chapada of the Veadeiros. The areas were divided between burned and unburned soils in three phytophysiognomies: Campo Limpo, Campo Sujo, and Stricto Senso. When the phytophysiognomies were compared, the Cleaned Field and the Dirty Field presented a greater increase of the TOC over time, with higher indices in burned soils, differentiated from the Stricto Senso where it occurred in the opposite way. In the fractions F1 + F2, Clean Field and Dirty Field obtained a significant increase in burned soils, in Stricto Senso there was a larger drop in values with the soil without burning with greater amount of carbon. In the F3 + F4 fractions in the Clean Field and Dirty Field, the highest values were found for the soils without burning, in Stricto Senso obtained higher values in burnt soil. 


\section{INTRODUÇÃO}

O bioma Cerrado é provavelmente a maior savana do planeta, abrangendo aproximadamente 2.000.000 km² (HENRIQUES, 2005). Também é um dos biomas mais ameaçados, o desmatamento é uma das principais preocupações por terem áreas propícias à agricultura e agropecuária.

O bioma Cerrado contém várias fitofisionomias: sendo campo limpo, campo sujo, stricto sensu, veredas e cerradão, sendo utilizado para este trabalho o campo limpo, que se caracteriza por sua vegetação com ausência total de árvores, e raramente se encontram arbustos, as vegetações predominantes são às herbáceas. Podem ser frequentemente encontradas em chapadas, em olhos d'água, em entorno de veredas e em bordas de matas de galerias, ocorrem em solos Litólicos, Litossolos, Cambissolos ou Plintossolos Pétricos.(RIBEIRO; WALTER, 1998).

Os Campos sujos são encontrados em solos mais rasos, como por exemplo, os Litólicos e com formações rochosas, em solos profundos e com baixar fertilidade. Sua vegetação é herbácea arbustiva, com arbustos e subarbustos espalhados, boa parte das plantas contêm os indivíduos menos desenvolvidos das espécies arbóreas do Cerrado sentido restrito (RIBEIRO; WALTER, 1998).

O Cerrado Sentido Restrito, também conhecido como Stricto Sensu, caracteriza-se por ter uma vegetação com árvores de menor porte, ainda tortuosas e retorcidas, ramificações irregulares, e com maior incidência de queimadas. Os solos são de predominância Latossolos, podem ocorrer Latossolo Vermelho Amarelo, Latossolo Vermelho Escuro e Latossolo Roxo, o
$\mathrm{pH}$ varia de 4,5 a 5,5, são solos com acidez moderada, necessidade de nutrientes essências como fósforo e nitrogênio (RIBEIRO; WALTER, 1998).

As queimadas e incêndios florestais são as principais causas da perda de biodiversidade e degradação dos recursos hídricos (MMA, 2011). Os incêndios modificam as características físicas, biológicas, químicas e morfológicas do solo, também há alteração na quantidade de carbono, nutrientes, na biodiversidade da micro, meso e macro fauna, e características como umidade, porosidade do solo e densidade (CAPECHE, 2012).

Os incêndios florestais é o fogo que não possui controle, sobre qualquer tipo de vegetação, podendo ocorrer de formas naturais, sendo ocasionadas por raios, ou de forma intencional através do homem, as queimadas são quando se à o controle do fogo, sendo utilizado em atividades agrícolas e florestais onde é utilizado de forma racional. (ICMBIO MMA, 2010), quando utilizado de forma racional e uma ferramenta importante para a ciclagem de nutrientes, e impedimento da perda de parte da diversidade florística sendo que cada vez mais espécies únicas do cerrado vem sendo extintas.

No ano de 2017 um incêndio de grandes proporções atingiu o Parque Nacional da Chapada dos Veadeiros, reduto de biodiversidade localizado no nordeste do Estado de Goiás, que protege uma área de 240.586,56 hectares de Cerrado. A área devastada pelo fogo foi de aproximadamente 66 mil hectares de vegetação.

A decomposição acelerada da matéria orgânica causa consequências ao solo que perde 
boa parte da sua fertilidade (SILVA; MACHADO, 2000). O fogo interfere diretamente na parte química do solo, diminui a CTC do solo, e faz com que solos fiquem mais ácidos.

Diante do exposto, objetivou-se com este trabalho avaliar os teores de Carbono Orgânico Total e suas frações oxidáveis dos solos em ambientes do Parque Nacional da Chapada dos Veadeiros e acompanhar a recuperação das áreas afetadas.

\section{MATERIAL E MÉTODOS}

As amostras de solo foram realizadas no Parque Nacional Chapada dos Veadeiros localizado a $14^{\circ} 10^{\prime} \mathrm{S}, 47^{\circ} 30^{\prime} \mathrm{W}$, sendo situada a nordeste do estado de Goiás entre as cidades de Alto paraíso de Goiás, Cavalcante e Colinas do sul. A Região possui clima semitropical de suave brisa, a temperatura media anual é de $25^{\circ}$, sendo que na primavera pode alcançar $40^{\circ}$, as chuvas nesta região vão de outubro a abril tendo media de precipitação entre $1.200 \mathrm{~mm}$ a $1.800 \mathrm{~mm}$ (CHAPADA DOS VEADEIROS, 2018).

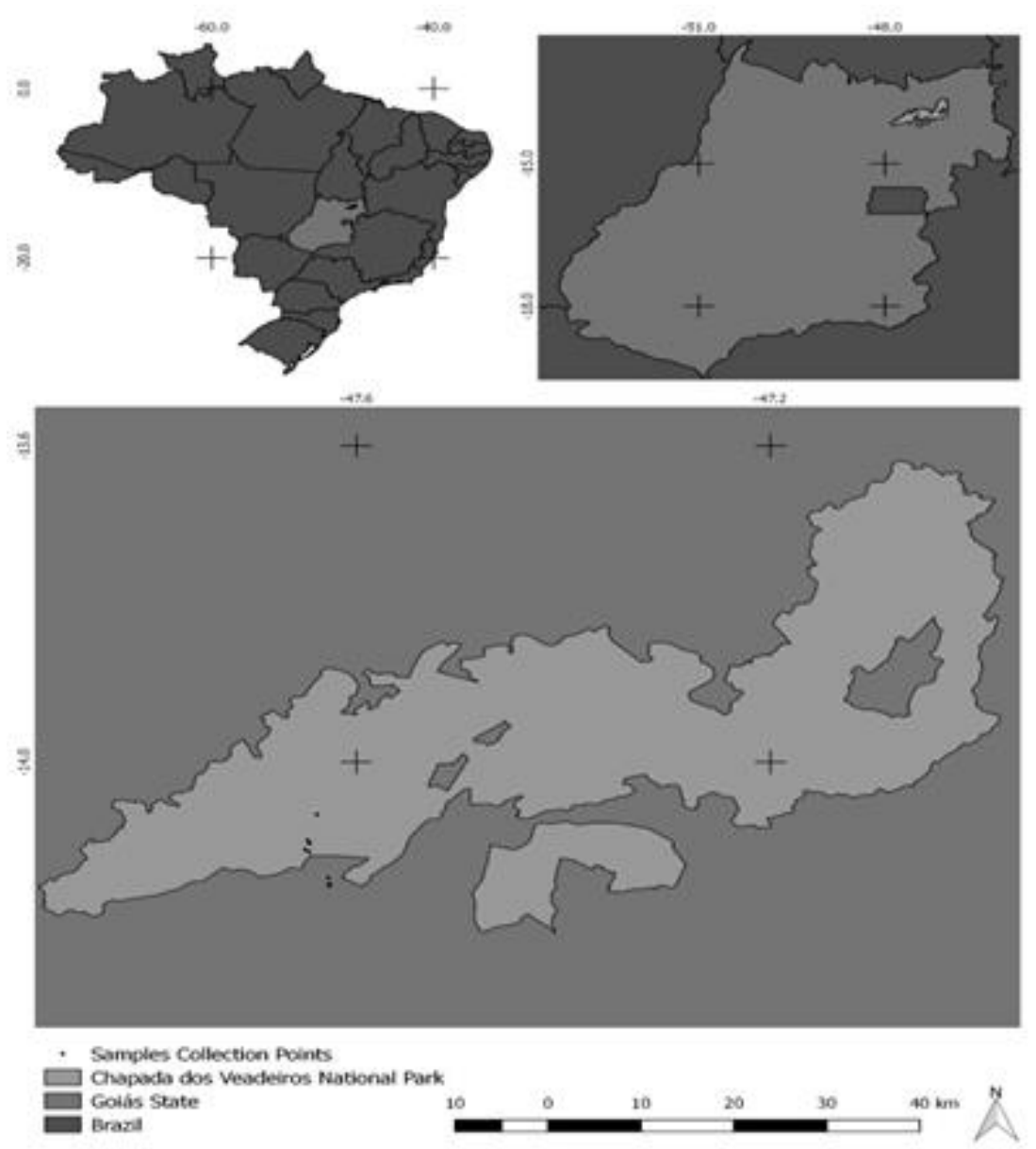

Figura1. Localização Parque Nacional Chapada dos Veadeiros.

Sendo uma unidade de conservação queimadas de 66 mil ha de vegetação, no dia 10 de brasileira de proteção integral à natureza, a reserva outubro de 2017.

sofreu uma catástrofe, sendo uma área de

Para efeito de avaliação dos teores de Carbono e respectivas frações foram coletadas 
amostras de solo na profundidade de 0,0 a 0,1 m em três fitofisionomias (Cerrado Stricto Sensu, Campo Limpo e Campo Sujo) em áreas atingidas e não atingidas pelo incêndio florestal. Foram realizadas três coletas. A primeira coleta, realizada em 10 de novembro de 2017, logo após o controle das chamas, a segunda em 11 de março de 2018 e a terceira no dia 23 de junho de 2018. Por ocasião da primeira coleta foram coletadas as coordenadas geográficas para que nas coletas subsequentes as amostras fossem retiradas nos mesmos locais (Figura 2)

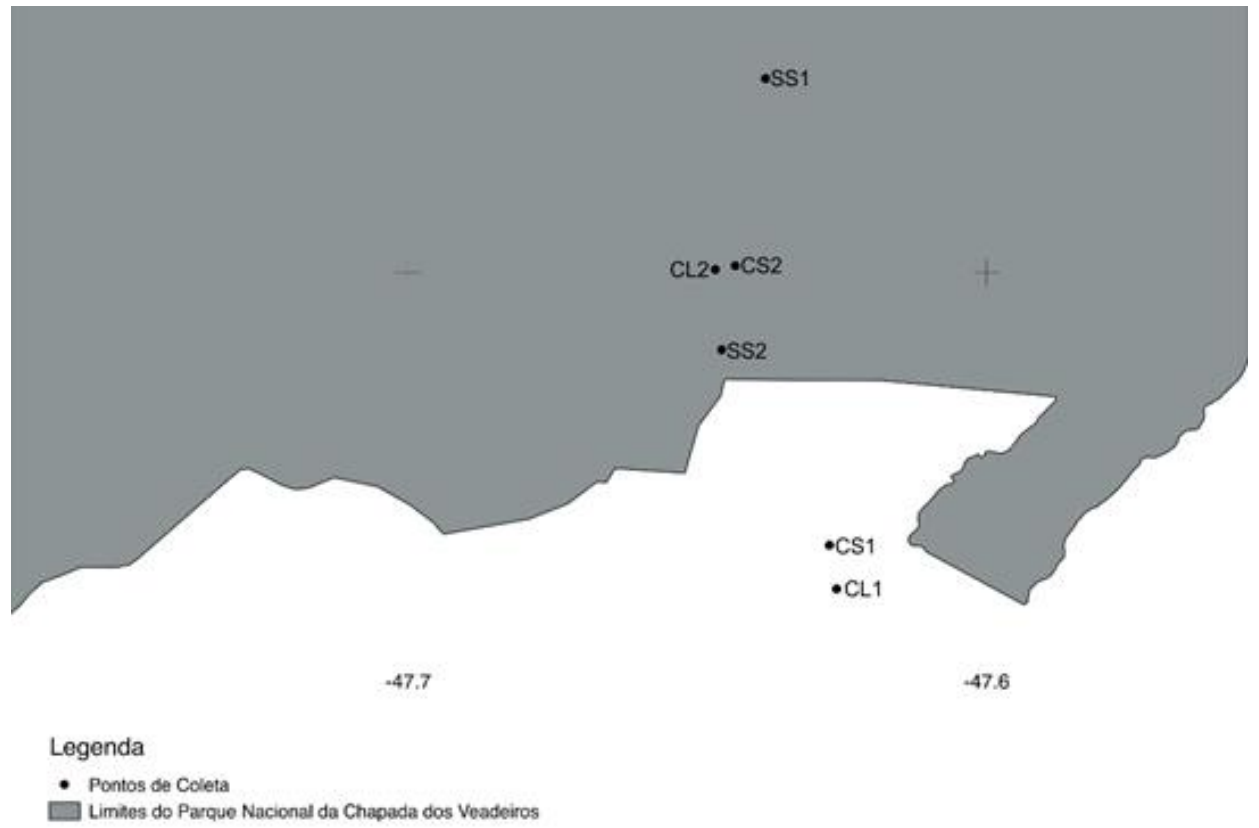

Figura 2. Pontos amostrais para avaliação dos teores de Carbono Orgânico Total e suas Frações Oxidáveis. CL1 - Campo Limpo sem queimada; CL 2 - Campo Limpo com queimada; CS1 - Campo Sujo sem queimada; CS2 - Campo Sujo com queimada; SS1 - Stricto Sensu sem queimada; SS2 - Stricto Sensu com queimada. Parque Nacional da Chapada dos Veadeiros.

As análises laboratoriais foram conduzidas na Faculdade Evangélica de Goianésia, situada na cidade de Goianésia-Go, onde foram secas ao ar, tamisadas em peneira de $0,50 \mathrm{~mm}$ e armazenadas até o momento das análises.

As frações oxidáveis da matéria orgânica foram determinadas de acordo com o procedimento proposto por Chan et al. (2001) adaptado por Rangel et al. (2008), amostras de 0,5g de terra fina seca ao ar (TFSA) foram colocadas em Erlenmeyers de $250 \mathrm{~mL}$, onde adicionaram-se 10 $\mathrm{mL} \mathrm{K}_{2} \mathrm{Cr}_{2} \mathrm{O}_{7}, 0,167 \mathrm{~mol} \mathrm{~L}^{-1}$ e quantidades de $\mathrm{H}_{2} \mathrm{SO}_{4}, \quad 2,5 \mathrm{ml}, \quad 5 \mathrm{ml}, \quad 10 \mathrm{ml}$ e $20 \mathrm{ml}$ correspondentes, concentrações finais de $3,6,9$ e $12 \mathrm{~mol} \mathrm{~L}^{-1}$. A oxidação foi realizada sem fonte externa de calor e a titulação dos extratos foi realizada com uma solução de FeSO. $\mathrm{H}_{2} \mathrm{O}$ 0,4 mol L-1 (Sal de Mohr), utilizou-se como indicador a fenantrolina $\left(\mathrm{C}_{12} \mathrm{H}_{8} \mathrm{~N}_{2} \mathrm{H}_{2} \mathrm{O}\right)$, preparada em função da mistura de $1,465 \mathrm{~g}$ de indicador com $0,985 \mathrm{~g}$ de $\mathrm{Fe}\left(\mathrm{NH}_{4}\right)_{2}\left(\mathrm{SO}_{4}\right)_{2} \cdot 6 \mathrm{H}_{2} \mathrm{O}$, que foram dissolvidos em $100 \mathrm{~mL}$ de água destilada. O fracionamento do C produziu quatro frações, com graus decrescentes de oxidação:

Fração 1 (F1): C oxidado por $\mathrm{K}_{2} \mathrm{Cr}_{2} \mathrm{O}_{7} \mathrm{em}$ meio ácido com $3 \mathrm{~mol} \mathrm{~L}^{-1}$ de $\mathrm{H}_{2} \mathrm{SO}_{4}$; 
Fração 2 (F2): diferença entre o C oxidado por $\mathrm{K}_{2} \mathrm{Cr}_{2} \mathrm{O}_{7}$ em meio ácido com 6 e $3 \mathrm{~mol} \mathrm{~L}^{-1}$ de $\mathrm{H}_{2} \mathrm{SO}_{4}$;

Fração 3 (F3): diferença entre o C oxidado por $\mathrm{K}_{2} \mathrm{Cr}_{2} \mathrm{O}_{7}$ em meio ácido com 9 e $6 \mathrm{~mol} \mathrm{~L}^{-1}$ de $\mathrm{H}_{2} \mathrm{SO}_{4}$;

Fração 4 (F4): diferença entre o C oxidado por $\mathrm{K}_{2} \mathrm{Cr}_{2} \mathrm{O}_{7}$ em meio ácido com 12 e $9 \mathrm{~mol} \mathrm{~L}^{-1}$ de $\mathrm{H}_{2} \mathrm{SO}_{4}$.

Para análise deste trabalho considerou-se a junção das frações F1 e F2 (Frações mais oxidáveis) e F3 e F4 (Frações mais estáveis).
Os dados obtidos em laboratório para as três coletas foram analisados por estatística descritiva, buscou entender a dinâmica do Carbono em ambientes que passaram por incêndios.

\section{RESULTADOS E DISCUSSÃO}

Os teores de Carbono Orgânico Total (COT) quando desprezados as fitofisionomias e ao realizar a avaliação apenas o efeito da queimada estão apresentados na Figura 3.

\section{Carbono Orgânico Total}

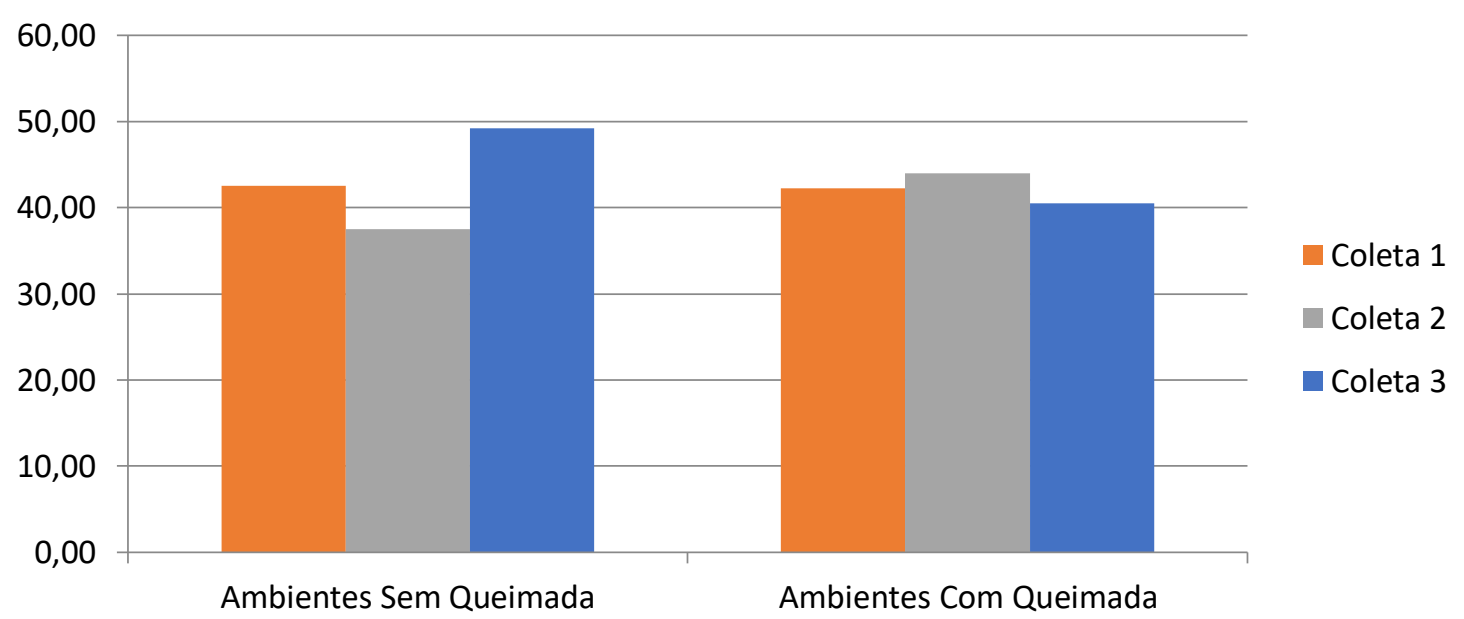

Figura 3. Teores de Carbono Orgânico Total (COT) em solos do Cerrado em diferentes coletas. Parque Nacional da Chapada dos Veadeiros, 2018

Os teores de COT variaram entre 37,47 e 49,24 $\mathrm{g} \mathrm{Kg}^{-1}$ para os ambientes sem queimada e 40,49 e 44,00 $\mathrm{g} \mathrm{Kg}^{-1}$ nas áreas atingidas pelo fogo e estão próximos aos valores considerados como limite de sustentabilidade de 40,0 $\mathrm{g} \mathrm{kg}^{-1}$, sendo o necessário para o solo se manter nutrido e sustentável com o carbono contido no solo, sugerido por Goedert (2005) e Papa (2011). Em relação às médias, observaram-se valores superiores para os ambientes sem queimada (43,07 $\left.\mathrm{g} \mathrm{Kg}^{-1}\right)$ em relação aos ambientes atingidos pelos incêndios $\left(42,24 \mathrm{~g} \mathrm{Kg}^{-1}\right)$. A principal explicação para o fato observado está relacionada com a maior emissão de $\mathrm{CO}_{2}$ para atmosfera em ambientes impactados pelo fogo, enquanto em ambientes não atingidos há maior acúmulo de Carbono no solo.

Nas frações mais lábeis (F1 + F2) foi observado incremento nos teores de Carbono do 
solo nos ambientes impactados pelo fogo. Os ambientes atingidos pelo incêndio florestal realizadas (Figura 4).

\section{F1+F2}

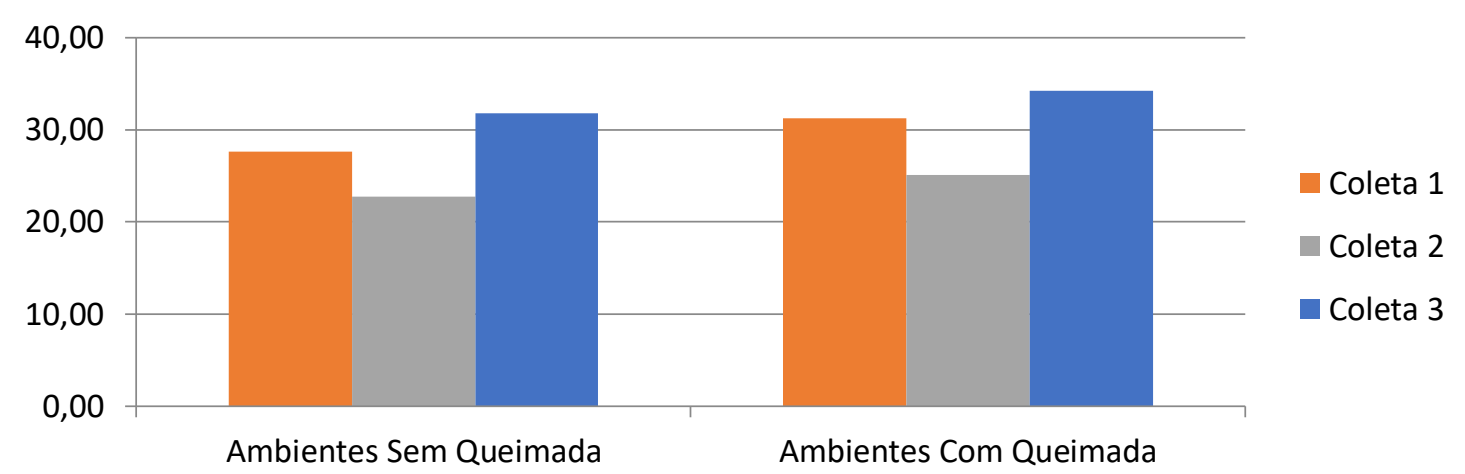

Figura 4.. Teores de carbono orgânico oxidável das frações F1 + F2, em solos do Cerrado em diferentes coletas. Parque Nacional da Chapada dos Veadeiros, 2018.

As frações F1 e F2 são consideradas as frações mais lábeis da matéria orgânica e são compostos por micro-organismos vivos ou mortos e materiais vegetal com menor quantidade de lignina. Nardoto e Bustamante (2003) estudaram o efeito do fogo sobre a biomassa microbiana do solo em áreas de Cerrado e observaram um rápido aumento na biomassa microbiana no solo logo após a queimada da área e também um ligeiro decréscimo após exaurir as fontes de energia aos micro-organismos. Loss et al. (2010) consideram estas frações de grande importância por serem responsáveis pela disponibilidade de nutrientes e estruturação do solo.

Para as frações F3+F4, observou-se uma variação entre ambientes, na primeira coleta foi encontrada na área sem queimada $18,84 \mathrm{~g} \mathrm{Kg}^{-1}$ e na área com queimada $11 \mathrm{~g} \mathrm{Kg}^{-1}$, já na segunda coleta a quantidade de carbono apresentou incremento da área sem queima para a área com queima, de 14,76 g $\mathrm{Kg}^{-1}$ para 18,93 $\mathrm{g} \mathrm{Kg}^{-1}$. Já na terceira coleta os valores tiveram uma queda da área sem queimadas para as com queimada, de $17,48 \mathrm{~g} \mathrm{Kg}^{-1}$ para 6,24 $\mathrm{g}$ $\mathrm{Kg}^{-1}$ (Figura 5).

\section{F3+F4}

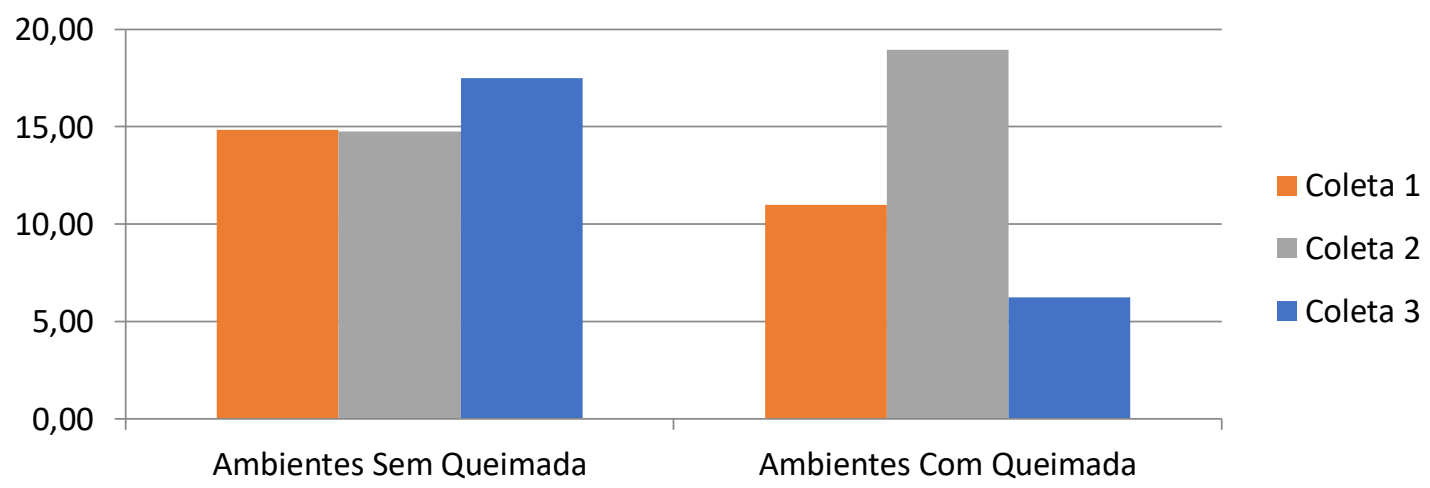

Figura 5. Teores de carbono encontrados em F3+F4, em solos do Cerrado em diferentes coletas. Parque Nacional da Chapada dos Veadeiros, 2018. 


\section{Carbono Orgânico Total}

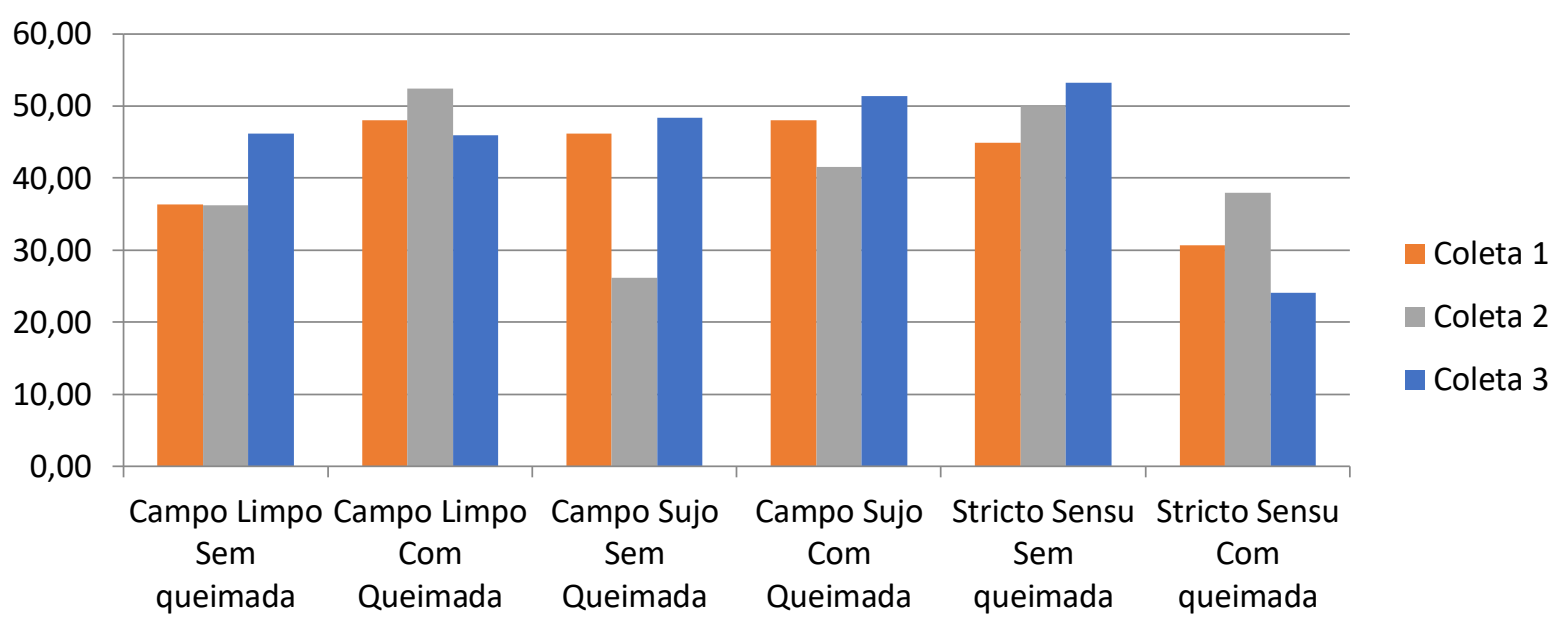

Figura 6. Teores de Carbono Orgânico Total (COT) em solos do Cerrado em diferentes fitofisionomias. Parque Nacional da Chapada dos Veadeiros, 2018.

Os valores para Carbono Orgânico Total dos solos ao considerar as diferentes fitofisionomias estão apresentados na Figura 6.

Para a fitofisionomia Campo Limpo observou-se maiores valores de Carbono Orgânico Total para as duas primeiras coletas em áreas sob queimadas. Já na terceira coleta, houve um equilíbrio dos teores neste ambiente. Os maiores valores encontrados nas áreas de queimadas mostram o efeito da queimada na maior mineralização dos tecidos vegetais que podem disponibilizar nutrientes e favorecer a rebrota e/ou germinação das espécies.

Para a fitofisionomia Campo Sujo apenas na segunda coleta os valores de COT apresentaram comportamento distinto entre as áreas com e sem queimadas. Para as coletas 1 e 3 os valores ficaram próximos o que mostra um equilíbrio e pouca influência do fogo nesta fitofisionomia.
Já no Stricto Senso houve uma redução nos valores de COT nos ambientes que sofreram com os incêndios. Tal fato pode estar relacionado com a maior quantidade de plantas de porte arbustivo e menor quantidade de plantas rasteiras e de baixo porte, o que contribui para menor deposição de material incinerado sobre o solo.

Entre as fitofisionomias nas frações F1 + F2, tanto para Campo Limpo quanto Campo Sujo, houve um aumento de $\mathrm{C}$ nos solos de queimadas sendo que no Campo Limpo obtiveram em média resultados de 13,7 $\mathrm{g} \mathrm{Kg}^{-1}$ para solos sem queimada e 35,56 $\mathrm{g} \mathrm{Kg}^{-1}$ para áreas com queimada. No Campo Sujo as médias foram de $25,88 \mathrm{~g} \mathrm{Kg}^{-1} \mathrm{em}$ solos sem queimada e 41,24 $\mathrm{g} \mathrm{Kg}^{-1}$ em solos com queimada, já no Stricto Senso houve uma queda, com média entre as três coletas de $42,54 \mathrm{~g} \mathrm{Kg}^{-1} \mathrm{em}$ solos sem queimada e de $13,73 \mathrm{~g} \mathrm{Kg}^{-1}$ para solos com queimada (Figura 7). 


\section{Frações F1+F2}

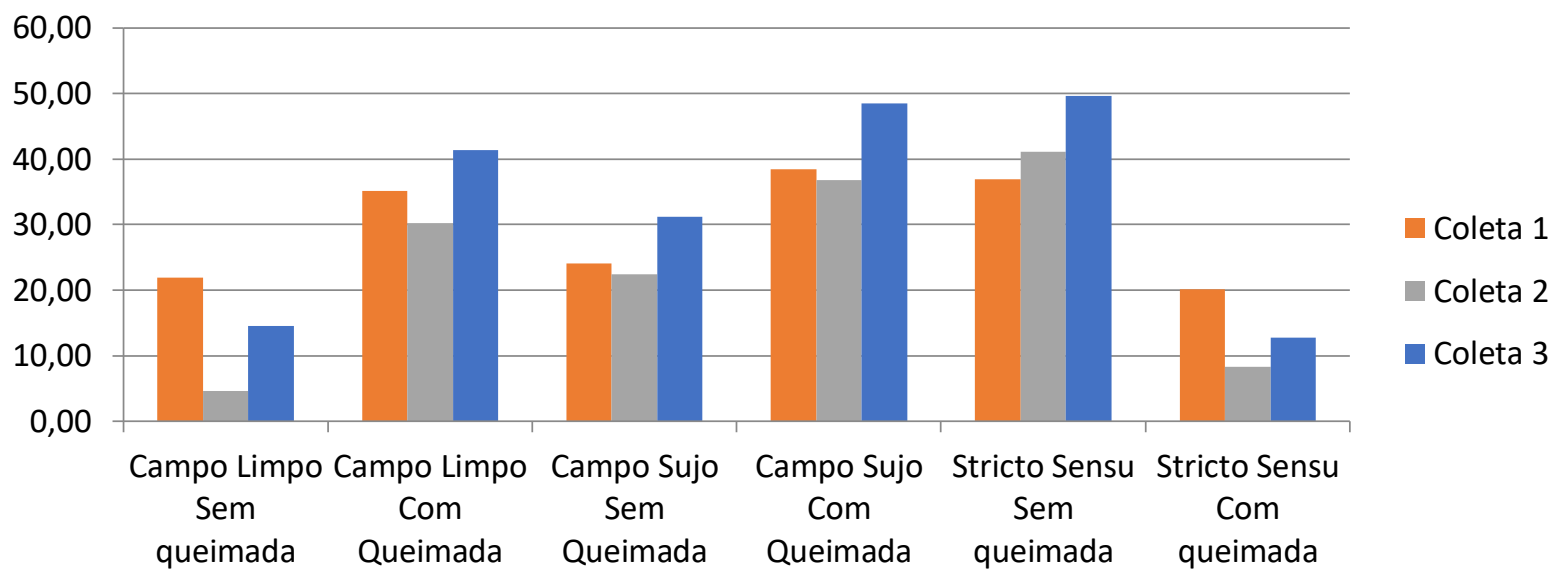

Figura 7. Teores de carbono orgânico nas frações F1+F2 em solos do Cerrado em diferentes fitofisionomias. Parque Nacional da Chapada dos Veadeiros, 2018.

Nas frações F3 e F4 o resultado obtido foi diferente das análises anteriores, pois mostrou que os solos sem queimadas apresentaram maiores teores de carbono e após a queimada foram diminuindo, em campo limpo onde obteve média de solos sem queimada de 25,9 $\mathrm{g} \mathrm{Kg}^{-1}$ para 13,24 $\mathrm{g}$ $\mathrm{Kg}^{-1}$ em solos com queimada, em campo sujo encontrou média de $14,34 \mathrm{~g} \mathrm{Kg}^{-1}$ em solos sem queimada e de $5,73 \mathrm{~g} \mathrm{Kg}^{-1}$ em solos com queimada, já no Stricto Senso foi exatamente ao contrário, o solo tinha média de $6,83 \mathrm{~g} \mathrm{Kg}^{-1}$ sem queimada e aumentou para $17,20 \mathrm{~g} \mathrm{Kg}^{-1}$ o solo com queimadas (Figura 8).

\section{Frações F3+F4}

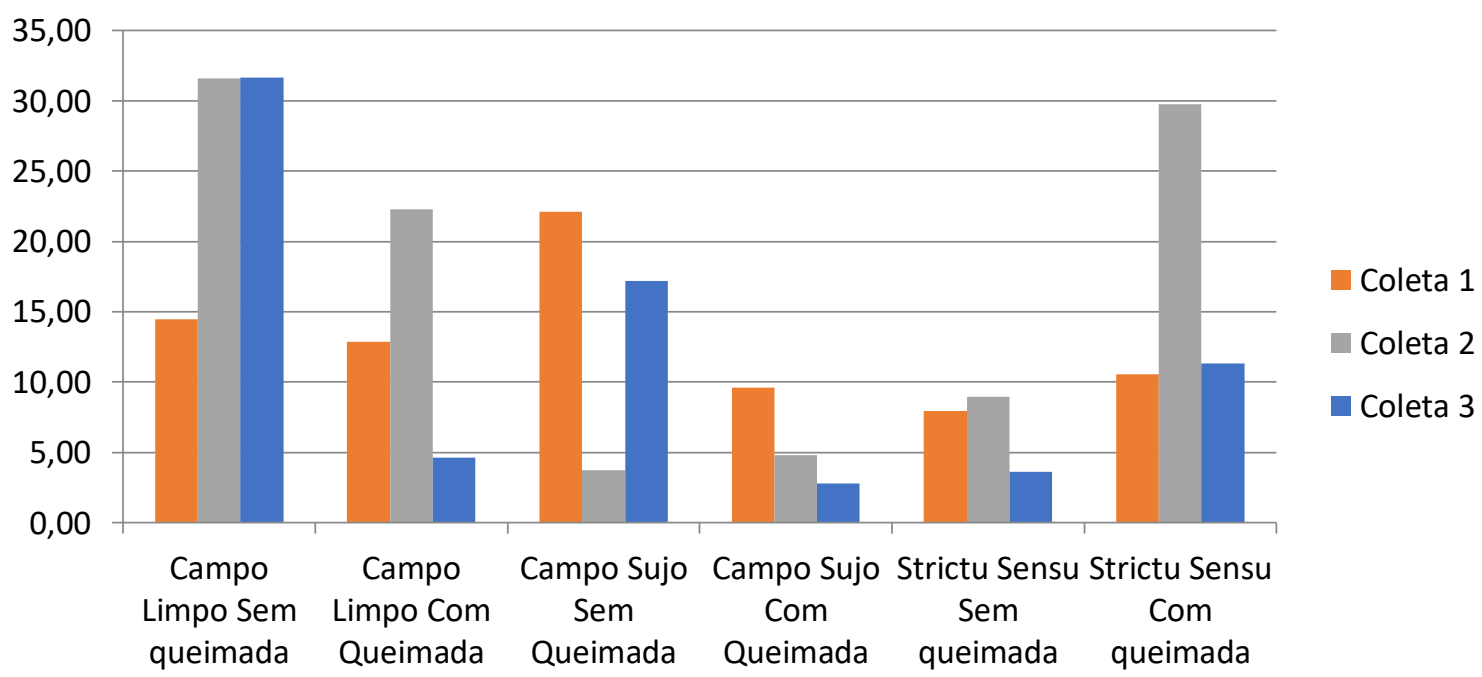

Figura 8. Teores de carbono nas frações F3+F4 em solos do Cerrado em diferentes fitofisionomias

Os resultados de Santin et al. (2008), acúmulo de carbono no solo, isso pode ser visto sugerem que alguns casos de incêndios florestais quando observamos os resultados do Stricto Senso ou em vegetações mais densas, contribui para o em relação as frações F3+F4 e também quando 
comparados os resultados de campo limpo e campo sujo nas frações $\mathrm{F} 1+\mathrm{F} 2$ onde há um aumento após a queimada. Já nas frações F1+F2 do Stricto Senso o carbono depositado no solo fica em uma camada superficial, sendo que um dos fatores que mais contribui para degradação e perda de nutrientes no solo são as erosões hídricas (SANTOS et al., 2007), ocorrendo também a lixiviação de elementos nas camadas superficiais do solo.

Assim, a partir dos resultados obtidos, o presente trabalho Colabora com Lozano et al. (2015) no que tange a recuperação das áreas atingidas por incêndios florestais, que afirmam que esta recuperação está atrelada a intensidade do fogo, quantidade de chuvas posteriores, as ações pós incêndio, dentre outros.

\section{CONCLUSÕES}

Nas áreas comparadas o carbono orgânico total entre ambientes teve um equilíbrio entre solos sem queimada e com queimada, nas frações F1+F2 houve um pequeno aumento no $\mathrm{C}$ do solo em áreas de queimadas, as frações F3+F4 houve uma perda maior nas áreas degradadas pelo fogo.

Quando comparadas as fitofisionomias, tanto o campo limpo quanto o campo sujo houve aumento do $\mathrm{C}$ no COT e nas frações F1+F2 e uma diminuição na F3+F4 nos solos de queimadas, e, já no Stricto senso ocorreu o contrário houve diminuição de carbono no COT e F1+F2, e aumento na F3+F4.

\section{REFERÊNCIAS BIBLIOGRÁFICAS}

CAPECHE C L. Impactos das Queimadas na Qualidade do Solo - Degradação Ambiental e Manejo e Conservação do Solo e Água. In: II Encontro Científico do Parque Estadual dos Três Picos. 2012, Cachoeiras de Macacu.-SP. Anais do II Encontro Científico do Parque Estadual dos Três Picos, São Paulo, 2012, p. 17-20.

CHAN, KY, BOWMAN A, OATES A .; Frações de carbono orgânico oxidável e mudanças na qualidade do solo em um palheiro de milhoamarelo sob diferentes faixas de pastagem. Ciência do Solo, v. 166, n. 1, p. 61-67, 2001.

\section{CHAPADA DOS VEADEIROS. Clima} chapada dos veadeiros. Disponível em: http://www.chapadaveadeiros.com.br/clim a chapada veadeiros.html. Acesso em: 19 de dez. de 2018.

GOEDERT WJ. Qualidade do solo em sistemas de produção agrícola. In: Congresso Brasileiro de Ciência Do Solo, 30. 2005. Anais... Recife: SBCS, 2005.

HENRIQUES RPB. Influência da história, solo e fogo na distribuição e dinâmica das fitofisionomias no bioma do Cerrado. In; SCARIOT, A., SOUSA-SILVA, J.C.; FELFILI, J.M. Cerrado: Ecologia, Biodiversidade e conservação. Brasília: Ministério do Meio Ambiente, 2005.

ICmbio MMA. Apostila para Formação de Brigadista de Prevenção e Combate aos Incêndios Florestais. Pag. 23. Brasília, 2010.

\section{LOZANO E, CHRENKOVA K, ARCENEGUI $\mathrm{V}$, JIMÉNEZ- PINILLA P, MATAIXSOLERA J, MATAIX- BENEYTO J. Resposta de proteínas do solo relacionadas à glomalina à temperatura de aquecimento: abordagem laboratorial. Degradação e desenvolvimento da terra. LDD-150155.R1, 2015.}

LOSS A, MORAES AGL, PEREIRA MG, SILVA EMR, ANJOS LHC. Carbono, matéria orgânica leve e frações oxidáveis do carbono orgânico sob diferentes sistemas de produção orgânica. Comunicata Scientiae, v. 1, p. 57-64, 2010. 
MINISTÉRIO DO MEIO AMBIENTE. Plano de ação para prevenção e controle do desmatamento e das queimadas: cerrado. Brasília, Ministério do Meio Ambiente. 2011. 200p.

NARDOTO GB, BUSTAMANTE MMC. Efeitos do fogo na dinâmica de nitrogênio do solo e biomassa microbiana em savanas do Brasil Central. Pesquisa Agropecuária Brasileira, Brasília, v. 38, n. 8, p. 955-962. 2003.

PAPA RA. Qualidade de Latossolos Vermelhos e Vermelho-Amarelos sob vegetação nativa de Cerrado. Pesquisa Agropecuária Tropical, v. 41, p. 564-571, 2011.

RANGEL OJP, SILVA CA, GUIMARÃES PTG, GUILHERME LRG. Frações oxidáveis do carbono orgânico de Latossolo cultivado com cafeeiro em diferentes espaçamentos de plantio. Ciência e Agrotecnologia, v. 32, p. 429-437, 2008.

RIBEIRO JF, WALTER BMT. Fitofisionomias do bioma cerrado. IN In: SANO SM,
ALMEIDA SP. de (Ed.). Cerrado: ambiente e flora. Planaltina: EMBRAPA-CPAC, 1998, 166p.

SANTÍN C, KNICKER H, FERNÁNDEZ S, MENÉNDEZ-DUARTE R, ÁLVAREZ MA. Incêndios florestais influenciam a matéria orgânica do solo na região montanhosa do Atlântico (NW da Espanha). Catena, Amsterdam, v. 74, n. 3, p. 286-295, 2008.

SANTOS TEM, MONTENEGRO AAA, SILVA EFF, LIMA NETO JA. Perdas de solo, água, nutrientes e carbono orgânico em Cambissolo e Latossolo sob chuva natural. Recife PE, Revista Brasileira de Ciências Agrarias, v2, n2, p. 142-149, 2007.

SILVA CA, MACHADO PLOA. Sequestro e emissão de carbono em ecossistemas agrícolas, estratégias para os aumentos dos estoques de matéria orgânica em solos tropicais. Rio de Janeiro: Embrapa solos 2000, p. 23 (Embrapa solos, Documento; 19). 